
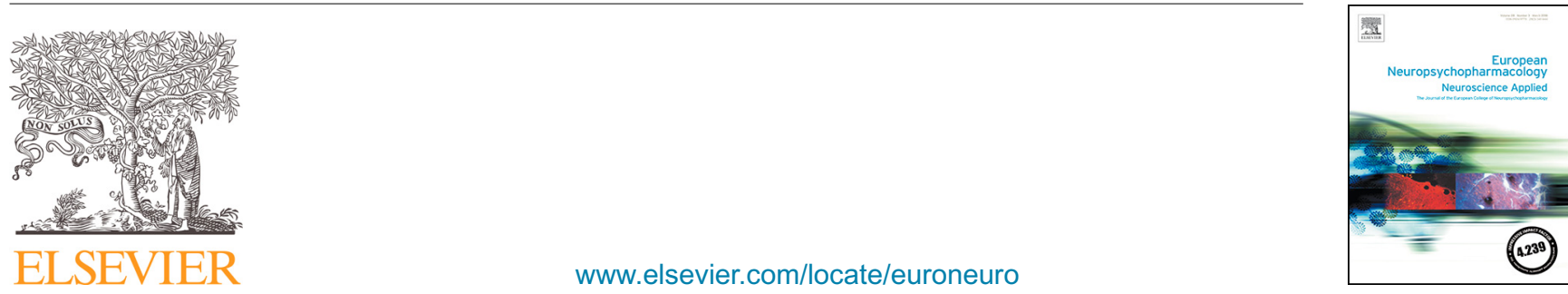

\title{
Neuroinflammation in the dorsolateral prefrontal cortex in elderly chronic schizophrenia
}

\author{
Irene López-González ${ }^{\mathrm{a}, 1}$, Raquel Pinacho ${ }^{\mathrm{b}, 1,2}$, Èlia Vila ${ }^{\mathrm{b}, \mathrm{c}}$, \\ Ana Escanilla ${ }^{c, d}$, Isidre Ferrer ${ }^{a, e, f, 3, *}$, Belén Ramos ${ }^{b, c, g, h, 3, * *}$
}

a Neuropathology, Bellvitge University Hospital, IDIBELL, L'Hospitalet de Llobregat, Barcelona, Spain

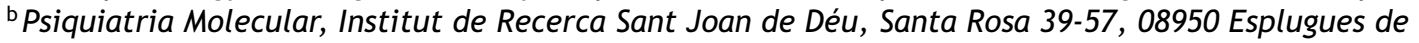

Llobregat, Spain

' Parc Sanitari Sant Joan de Déu, Dr. Antoni Pujadas, 42, 08830 Sant Boi de Llobregat, Spain

${ }^{\mathrm{d}}$ Banc de Teixits Neurologics, Parc Sanitari Sant Joan de Déu, 08830 Sant Boi de Llobregat, Spain

e Departament de Patologia i Terapeutica Experimental, University of Barcelona, L'Hospitalet de Llobregat, Barcelona, Spain

${ }^{f}$ CIBERNED (Biomedical Network Research Center of Neurodegenerative Diseases), Ministry of Economy, Industry and Competitiveness Institute of Health Carlos III, Madrid, Spain

${ }^{g}$ Centro de Investigación Biomédica en Red de Salud Mental, CIBERSAM (Biomedical Network Research Center of Mental Health), Ministry of Economy, Industry and Competitiveness Institute of Health Carlos III, Madrid, Spain

${ }^{\mathrm{h}}$ Dept. de Bioquímica i Biologia Molecular, Facultat de Medicina, Universitat Autònoma de Barcelona, Bellaterra, 08193 Barcelona, Spain

Received 22 May 2018; received in revised form 7 November 2018; accepted 16 December 2018

Available online $x x x$

\section{KEYWORDS}

Neuroinflammation;

Microglia;

Immune system;

\begin{abstract}
Cognitive deterioration and symptom progression occur in schizophrenia over the course of the disorder. A dysfunction of the immune system/neuroinflammatory pathways has been linked to schizophrenia (SZ). These altered processes in the dorsolateral prefrontal cortex (DLPFC)
\end{abstract}

\footnotetext{
* Corresponding author at: Departament de Patologia i Terapeutica Experimental, Universitat de Barcelona, carrer Feixa Llarga sn, Hospitalet de Llobregat, 08907, Spain.

** Corresponding author at: Psiquiatria Molecular, Institut de Recerca Sant Joan de Déu, Parc Sanitari Sant Joan de Déu, Dr. Antoni Pujadas, 42, 08830 Sant Boi de Llobregat, Spain.

E-mail addresses: 8082ifa@gmail.com (I. Ferrer), bramos@fsjd.org (B. Ramos).

${ }^{1}$ These authors contributed equally to the study.

2Present address: Department of Pharmacology, University of Oxford, Mansfield Road, Oxford OX1 3QT, UK.

3 Joint senior authors.
} 
Dorsolateral prefrontal cortex; Elderly schizophrenia could contribute to the worsening of the deficits. However, limited studies are available in this brain region in elderly population with long-term treatments. In this study, we explore the possible deregulation of 21 key genes involved in immune homeostasis, including pro- and antiinflammatory cytokines, cytokine modulators (toll-like receptors, colony-stimulating factors, and members of the complement system) and microglial and astroglial markers in the DLPFC in elderly chronic schizophrenia. We used quantitative real-time reverse transcriptase polymerase chain reaction (RT-PCR) on extracts from postmortem DLPFC of elderly subjects with chronic SZ $(n=14)$ compared to healthy control individuals $(n=14)$. We report that CSF1R, TLR4, IL6, TNF $\alpha$, TNFRSF1A, IL10, IL10RA, IL10RB, and CD68 were down-regulated in elderly SZ subjects. Moreover, we found that the expression levels of all the altered inflammatory genes in SZ correlated with the microglial marker CD68. However, no associations were found with the astroglial marker GFAP. This study reveals a decrease in the gene expression of cytokines and immune response/inflammation mediators in the DLPFC of elderly subjects with chronic schizophrenia, supporting the idea of a dysfunction of these processes in aged patients and its possible relationship with active microglia abundance. These findings include elements that might contribute to the cognitive decline and symptom progression linked to DLPFC functioning at advanced stages of the disease.

(C) 2018 Elsevier B.V. and ECNP. All rights reserved.

\section{Introduction}

Schizophrenia (SZ) is a chronic psychiatric disorder characterized by positive (e.g., hallucinations and delusions), negative (e.g., apathy and impaired motivation), and cognitive symptoms (e.g., poor performance in executive functions and attention). The dorsolateral prefrontal cortex (DLPFC) has been reported to contribute to cognitive deficits (e.g., executive function, working memory, and attention) (Sakurai et al., 2015; Teffer and Semendeferi, 2012) and negative symptoms (Toda and Abi-Dargham, 2007). Both cognitive deficits and negative symptoms are present in some people with a first episode psychosis and ultra-high risk for psychosis, suggesting that these deficits are present in prodromal phases before the onset of the disease (Bora and Murray, 2014; Foussias et al., 2015; Stahl and Buckley, 2007; Zabala et al., 2010). Moreover, some studies show greater cognitive decline with increased numbers of relapses (Xiang et al., 2011). Chronic inflammation in the DLPFC has been suggested as a possible neurobiological basis of cognitive deterioration over the course of the disease (Meyer, 2013). Supporting the idea that inflammation and also immune dysfunction play a role in the deficits observed in SZ are epidemiological, biomolecular, and genetic studies, and clinical trials with anti-inflammatory drugs (Gibney and Drexhage, 2013; Kirkpatrick and Miller, 2013; Müller, 2017). Together, these studies raise the possibility that dysfunction of neuroinflammation and the immune system might contribute to the deficits observed in the DLPFC related to the worsening of the symptoms and cognitive decline in elderly chronic SZ.

Several lines of evidence from epidemiological studies have demonstrated that prenatal exposure to maternal immune activation, such as by maternal exposure to infectious diseases during pregnancy, has been associated with SZ in adult offspring (Brown, 2011; Brown et al., 2004; Brown and Derkits, 2010; Canuti et al., 2015; Khandaker et al., 2013). Pro-inflammatory cytokines may be important mediators between prenatal exposure and risk of SZ
(Gilmore and Jarskog, 1997; Müller et al., 2015). Several cytokines have been analysed in the serum and/or plasma of SZ patients, providing evidence of peripheral inflammatory changes in SZ. For instance, higher levels of proinflammatory cytokines such as interleukin $6,1 \beta$ and TNF $\alpha$ have been reported in the serum of chronic SZ cases (Kunz et al., 2011; Miller et al., 2011; Potvin et al., 2008; Xu et al., 1994). Moreover, a recent meta-analysis of blood cytokine alterations in schizophrenia revealed a different pattern of alteration for IL6 and TNF $\alpha$ depending on the clinical status (Goldsmith et al., 2016).

Inflammation occurs in the brain of individuals with SZ. In the brain, cytokines are synthesized and secreted mainly by microglia. The activation of microglial cells is related with the increase of pro-inflammatory cytokines and free radicals in SZ (Monji et al., 2013, 2009). Indeed, some antipsychotics possess anti-inflammatory properties by preventing microglial activation, suggesting that the control of microglia could have a role in the treatment of SZ (Kato et al., 2011; Sato-Kasai et al., 2016). Using positron emission tomography (PET) and radio-labeled ligands for the $18 \mathrm{kDa}$ translocator protein (TSPO), which is expressed in the mitochondria of activated microglia, it is possible to index microglia activation in vivo (Cagnin et al., 2001). PET studies have shown inconsistent results. Whereas some PET studies have identified microgliosis in middle-aged patients within the schizophrenia spectrum who were recovering from psychosis (Doorduin et al., 2009) or in schizophrenia patients within the first 5 years of disease onset (van Berckel et al., 2008), other PET studies have revealed no microglial activation in patients when compared with controls (Coughlin et al., 2016; Hafizi et al., 2017; Kenk et al., 2015; van der Doef et al., 2016) or decreased TSPO expression in patients with first-episode psychosis (Colleste et al., 2017). Post-mortem studies in mostly chronic middle-age schizophrenia subjects have demonstrated microglial activation in SZ (Bayer et al., 1999; Busse et al., 2012; Radewicz et al., 2000; van Kesteren et al., 2017; Wierzba-Bobrowicz et al., 2005). However, other studies have not demonstrated 
Table 1 Demographic, clinical and tissue-related features of cases $(n=28)$.

\begin{tabular}{|c|c|c|c|c|}
\hline & Schizophrenia $(n=14)$ & Non-psychiatric controls $(n=14)$ & Statistic & $p$-value \\
\hline Gender & Male- $100 \%(n=14)$ & Male- $100 \%(n=14)$ & N/A & $\mathrm{N} / \mathrm{A}$ \\
\hline Age at death & $76 \pm 11$ years & $71 \pm 8$ years & $1.42 ; 26$ & 0.1675 \\
\hline PMD & $4.8 \pm 2.8 h$ & $5.8 \pm 1.9 h$ & $1.23 ; 26$ & 0.2307 \\
\hline $\mathrm{pH}$ & $6.80 \pm 0.23$ & $6.78 \pm 0.54$ & $0.16 ; 26$ & 0.8738 \\
\hline RIN & $7.48 \pm 0.49$ & $7.70 \pm 0.59$ & $1.08 ; 26$ & 0.2911 \\
\hline Age of onset of illness & $26 \pm 10$ & N/A & $\mathrm{N} / \mathrm{A}$ & N/A \\
\hline Duration of illness & $50 \pm 10$ & N/A & N/A & N/A \\
\hline Daily AP dose ${ }^{1}$ & $367.14 \pm 339.58$ & N/A & $\mathrm{N} / \mathrm{A}$ & N/A \\
\hline AP free & $28.6 \%(n=4)$ & N/A & N/A & N/A \\
\hline Typical AP & $21.4 \% n=3)$ & N/A & N/A & N/A \\
\hline Atypical AP & $50.0 \%(n=7)$ & N/A & $\mathrm{N} / \mathrm{A}$ & N/A \\
\hline PANSS clinical scores & $(n=9)$ & N/A & N/A & N/A \\
\hline Positive & $24.63 \pm 7.89$ & N/A & N/A & N/A \\
\hline Negative & $25.75 \pm 5.63$ & N/A & N/A & N/A \\
\hline General & $50.00 \pm 9.40$ & N/A & N/A & N/A \\
\hline
\end{tabular}

Mean \pm standard deviation or relative frequency are shown for each variable; PMD, post-mortem delay; RIN, RNA integrity number; AP, antipsychotic; PANSS, Positive and Negative Syndrome Scale; N/A, not applicable. All deaths were due to natural causes. T-statistic and degrees of freedom are shown. The neuropathological categorization of associated sporadic Alzheimer's disease-related changes (See methods section: 0-I, II, III) which was performed according to the Braak and Braak nomenclature adapted for paraffin sections (Braak et al., 2006; Braak and Braak, 1991) did not show differences between groups $\left(\chi^{2}=0.000\right.$; degrees of freedom $=2, p$ value $\left.=1.00\right)$. ${ }^{1}$ Last chlorpromazine equivalent dose was calculated based on the electronic records of drug prescriptions of the patients.

abnormal microglial density in this profile of patients (Arnold et al., 1998; Steiner et al., 2008, 2006). Interestingly, recent messenger RNA (mRNA) sequencing (RNASeq) and reverse transcription quantitative PCR studies have shown an increase in inflammatory mRNA expression (IL6, $T N F \alpha, I L 8, I L 1 B$ and NF- $k B$ ) in post-mortem brains of subsets of patients with SZ (Fillman et al., 2013; Pandey et al., 2018; Volk et al., 2015). Additionally, one of these postmortem studies showed that an increase in microgliosis was accompanied by an increase in the cytokine expression levels of IL1B in the same region (Fillman et al., 2013).

Most studies of inflammatory and immune genes have included middle-aged subjects with SZ; however, the inflammatory and immune events altered in elderly chronic patients in SZ are much less studied. In this study, we examine, using a large panel of mRNA probes, the gene expression modulation of cytokines and mediators of the immune response in the dorsolateral prefrontal cortex in elderly chronic SZ individuals with long-term treatment. The selection of these probes was based on the fact that the same genes were evaluated in our previous studies of several neurodegenerative diseases also with neuroinflammatory components (Garcia-Esparcia et al., 2014; Llorens et al., 2014; López-González et al., 2015a, 2015b; López González et al., 2016). We decided to study the same panel of genes from inflammatory pathways in schizophrenia in the present study with the aim, in the future, of comparing these genes across different neuropsychiatric diseases. Moreover, microglial and astroglial markers were also included in this study. Consequently, twenty-one mRNAs, including pro- and anti-inflammatory cytokines, cytokine modulators (toll-like receptors, colony-stimulating factors, and members of the complement system) and astroglial and microglial markers were assessed in post-mortem tissue from the dorsolateral prefrontal cortex of elderly SZ patients compared to healthy controls.

\section{Experimental procedures}

\subsection{Brain human samples}

Human brain tissue was obtained from the neurologic tissue collection of the Parc Sanitari Sant Joan de Déu and the Institute of Neuropathology Brain Bank (HUB-ICO-IDIBELL Biobank, Barcelona, Spain) following Spanish legislation guidelines and approval by local ethics committees. Post-mortem tissue from the dorsolateral prefrontal cortex of a total of 28 human brains, including 14 control cases with no history of psychiatric episodes and 14 elderly subjects with chronic SZ, were included in the present study. We matched schizophrenia and control cases by gender, age, post-mortem delay, brain $\mathrm{pH}$, and the histological stage of Alzheimer disease (AD) (Braak et al., 2006; Braak and Braak, 1991). A summary of all the cases analysed in this study is shown in Table 1 . All SZ subjects were institutionalized donors with long-term illness (Table 1); neither control nor SZ subjects had a history of neurological diseases. Experienced clinical examiners interviewed each donor ante-mortem to confirm SZ diagnosis according to DSM-IV and ICD-10 criteria. Our study included the following schizophrenia diagnoses: chronic residual schizophrenia $(78.6 \%, n=11)$, chronic paranoid schizophrenia (14.3\%, $n=2)$, and chronic disorganized schizophrenia $(7.1 \%$, $n=1)$. Moreover, donor subjects were evaluated ante-mortem with the Positive and Negative Syndrome Scale (PANSS). Only associations between negative symptoms and gene expression data were performed for those subjects with a clinical assessment-to-death interval shorter than 48 months (Table 1). The last mean daily chlorpromazine equivalent dose for the antipsychotic treatment of patients was based on the electronic records of the last drug prescriptions administered up to the time of death (Table 1) and was calculated as previously described (Gardner et al., 2010). Three of the patients were being medicated with first-generation antipsychotics $(21.4 \%)$, seven were being medicated with secondgeneration antipsychotics (50\%), and four were antipsychotic-free $(28,6 \%)$.

One hemisphere was immediately cut into coronal sections, $1 \mathrm{~cm}$ thick, and selected areas of the encephalon were rapidly dissected, frozen on metal plates over dry ice, placed in individual 
Table 2 TaqMan probes used for the study of expression of cytokines and mediators of the immune response in the dorsolateral prefrontal cortex in control and schizophrenia samples, including probe used for normalization (XPNPEP1).

\begin{tabular}{|c|c|c|}
\hline Symbol & Name of the gene & Reference \\
\hline$\overline{G U S B}$ & Glucuronidase, beta & Hs00939627_m1 \\
\hline HPRTT1 & Hypoxanthine phosphoribosyltransferase 1 & Hs02800695_m1 \\
\hline XPNPEP1 & X-prolyl aminopeptidase (aminopeptidase P) 1 & Hs00958026_m1 \\
\hline C1QL1 & Complement component 1 , q subcomponent 1 & Hs00198578_m1 \\
\hline C1QTNF7 & $\mathrm{C} 1 \mathrm{q}$ and tumor necrosis factor related protein 7 & Hs00230467_m1 \\
\hline C3AR1 & Complement component 3a receptor 1 & Hs00377780_m1 \\
\hline CSF1R & Colony stimulating factor 1 receptor & Hs00911250_m1 \\
\hline CSF3R & Colony stimulating factor 1 receptor & Hs00167918_m1 \\
\hline TLR4 & Toll-like receptor 4 & Hs01060206_m1 \\
\hline$T L R 7$ & Toll-like receptor 7 & Hs00152971_m1 \\
\hline IL8 & Interleukin 8 & Hs00174103_m1 \\
\hline IL1B & Interleukin $1 \beta$ & Hs01555410_m1 \\
\hline IL6 & Interleukin 6 & Hs00985639_m1 \\
\hline II6ST & Interleukin 6 signal transducer & Hs00174360_m1 \\
\hline$T N F \alpha$ & Tumor necrosis factor $\alpha$ & Hs01113624_g1 \\
\hline TNFRSF1A & Tumor necrosis factor receptor superfamily member $1 \mathrm{a}$ & Hs01042313_m1 \\
\hline IL10 & Interleukin 10 & Hs00961622_m1 \\
\hline IL10RA & Interleukin 10 receptor $\alpha$ & Hs00155485_m1 \\
\hline IL10RB & Interleukin 10 receptor $\beta$ & Hs00988697_m1 \\
\hline TGB1 & Transforming growth factor $\beta 1$ & Hs00998133_m1 \\
\hline TGB2 & Transforming growth factor $\beta 2$ & Hs00234244_m1 \\
\hline AlF1 & Allograft Inflammatory Factor 1 & Hs00741549_g1 \\
\hline CD68 & CD68 molecule & Hs02836816_g1 \\
\hline GFAP & Glial fibrillary acidic protein & Hs00909233_m1 \\
\hline
\end{tabular}

air-tight plastic bags, numbered with water-resistant ink, and stored at $-80^{\circ} \mathrm{C}$. The other hemisphere was fixed by immersion in $4 \%$ buffered formalin for 3 weeks for morphological studies. The neuropathological categorization of associated sporadic Alzheimer's disease-related changes was performed according to the Braak and Braak classification adapted for paraffin sections (Braak et al., 2006; Braak and Braak, 1991). Alzheimer's disease-related pathology stages IV-VI of Braak and Braak were not included in the present study and the occurrence of lower stages was balanced between control and schizophrenia cases: I or less (SZ:35.7\% $(n=5)$; Control: $35.7 \%(n=5))$; II (SZ: $50.0 \%(n=7)$; Control:50.0\% $(n=7))$; III (SZ:14.3\% $(n=2)$; Control:14.3\% $(n=2))$. Specimens of the DLPFC (Brodmann area BA9), extending from the pial surface to white matter and only including grey matter, were dissected and stored at $-80^{\circ} \mathrm{C}$.

\subsection{Reverse transcription quantitative PCR (RT-qPCR)}

Total RNA was extracted from the dorsolateral prefrontal cortex using Trizol reagent (Sigma-Aldrich) following the manufacturer's protocol. First strand cDNA was synthesized from $2 \mu \mathrm{g}$ of RNA using SuperScript III (Invitrogen). The RNA concentration of each sample was obtained from A260 measurements with a Nanodrop 2000 (Thermo Scientific, Wilmington, DE). RNA integrity was tested using an Agilent 2100 BioAnalyzer (Agilent Technologies, Palo Alto, CA). TaqMan qPCR assays for each gene were conducted in duplicate on cDNA samples in 384-well optical plates using an ABI Prism 7900 Sequence Detection system (Applied Biosystems, Life Technologies, Waltham, MA, USA). For each $10 \mu \mathrm{L}$ TaqMan reaction, $4.5 \mu \mathrm{L}$ cDNA diluted $1 / 10$ were mixed with $0.5 \mu \mathrm{L}$ 20x TaqMan Gene Expression Assays and $5 \mu \mathrm{L}$ of $2 x$ TaqMan Universal PCR Master Mix (Applied Biosystems). The reactions were performed using the following parameters: $50^{\circ} \mathrm{C}$ for $2 \mathrm{~min}, 95^{\circ} \mathrm{C}$ for $10 \mathrm{~min}$, and 40 cycles of $95^{\circ} \mathrm{C}$ for
$15 \mathrm{~s}$ and $60^{\circ} \mathrm{C}$ for $1 \mathrm{~min}$. Finally, TaqMan PCR data were captured using the Sequence Detection Software (SDS version 2.2, Applied Biosystems). TaqMan probes used in this study are shown in Table 2. Standard deviation and the coefficient of variation of the CT measures were lower than 0.39 and 1.30 , respectively, with the exception of one determination where the standard deviation was higher than 1 CT and therefore, excluded from the analysis. Samples were analysed with the double-delta cycle threshold $(\Delta \Delta C T)$ method. Briefly, the $C_{T}$ of each target mRNA was normalized against that of the housekeeping gene XPNEP1 $\left(C_{T}{ }^{\text {target gene }} C_{T}{ }^{X P N E P 1}\right)$, thereby obtaining the difference of $C T$ for each target gene $\left(\Delta C_{T}\right)$. Then, from each target gene, $\Delta \Delta \mathrm{C}_{\mathrm{T}}$ was calculated representing the $\Delta \mathrm{C}_{\mathrm{T}}$ of each sample normalized to the $\Delta \mathrm{CT}$ of the internal control: $\Delta \Delta C_{T}=\left(\Delta C_{T}\right.$ GENE (sample) $-\Delta C_{T}$ GENE (healthy subject $)$. Finally, partial fold change was calculated for each target $\left(2^{-\Delta \Delta C T}\right)$. The selection of beta glucuronidase (GUSB), X-prolyl aminopeptidase (aminopeptidaseP) (XPNPEP1), and hypoxanthine-guanine phosphoribosyltransferase (HPRT) as possible housekeeping genes was based on previous studies in post-mortem brain (Barrachina et al., 2006; Durrenberger et al., 2012; Meyronet et al., 2015). The most stable control gene from the three genes was determined using geNorm and NormFinder software (Andersen et al., 2004; Vandesompele et al., 2002). XPNEP1 was found to be the most stable gene and thus selected as the normalization gene for the study (Fig. S1A).

\subsection{Statistical analysis}

The normality of distribution of fold change values between controls and SZ subjects was analysed with the Kolmogorov-Smirnov test. The non-parametric Mann-Whitney test was performed to compare each group when they did not follow a normal distribution, while the unpaired t-test was used for normal variables. Outliers were detected where indicated using Pierce's criterion (as sim- 
plified by Gould) (Ross, 2003) for non-parametric variables, and Grubbs' test for parametric variables. The False Discovery Rate (FDR) with the Benjamini and Hochberg method (Benjamini and Hochberg, 1995) was computed for all the $p$-values resulting from our study. The FRD threshold was set at 0.1 . Bivariate analyses were carried out to detect association of our variables with potential confounding factors (age, post-mortem delay, pH, and RIN; and in the SZ group, with daily antipsychotic dose, age of onset, and duration of the illness), using Spearman or Pearson correlations for quantitative variables, for non-parametric variables and for parametric variables, respectively. Multiple linear regression models with a stepwise forward procedure performed after including significant related variables were used to adjust significant differences when needed. Statistical analysis was performed with GraphPad Prism version 5.01 and SPSS 24. The significance level was set at $p<0.05$.

\section{Results}

The SZ group did not show significant differences compared to the control group in demographic and tissue-related variables (Table 1). We analysed the gene expression of cytokine modulators (members of the complement system (C1QL1, C1QTNF7, C3AR1), colony stimulating factor receptors (CSF1R, CSF3R), Toll family (TLR4, TLR7)), proinflammatory cytokines (interleukins (IL1B, IL8, IL6, IL6ST), TNF $\alpha$ family (TNFRSF1A, TNF $\alpha$ )) and anti-inflammatory cytokines (IL10 family (IL10, IL10RA, IL10RB) and TGF $\beta$ family (TGF $\beta 1, T G F \beta 2)$ ) in the dorsolateral prefrontal cortex of elderly subjects with chronic SZ $(n=14)$ and controls $(n=14)$. XPNEP1 gene expression was used to normalize the mRNA levels. No differences were observed in XPNPEP1 expression between control and SZ groups (Fig. S1B). Among the cytokine modulators, we found that CSF1R and TLR4 mRNA expression levels were significantly down-regulated in SZ cases compared to control subjects (Fig. 1). In the proinflammatory genes, IL6, TNF $\alpha$, and TNFRSF1A mRNA expression levels were significantly decreased in SZ compared to control subjects (Fig. 2). Concerning anti-inflammatory cytokines, three out of five analysed genes showed significant reduction in SZ compared with controls, including ILI0, IL10RA, and IL10RB (Fig. 3).

We also investigated the expression levels of microglial markers (AIF1 and CD68) and the astroglial marker GFAP. No altered expression levels for the astrocyte marker GFAP were found in SZ samples compared to controls. For the microglial markers AIF1 (which encodes IBA1) and CD68 (reactive microgliosis), only CD68 mRNA expression levels were significantly decreased in the dorsolateral prefrontal cortex of SZ patients (Fig. 4).

To further investigate the possible relationship between altered microglial (CD68) and altered inflammatory genes, we tested whether there were any associations between them. We found that all the expression levels of the altered inflammatory genes in SZ significantly correlated with the microglial marker CD68 (Table 3). In addition, no associations were found for any significantly altered gene with the severity of negative symptoms measured by PANSS (Table S1).

Association analysis of other variables in the study (age, post-mortem delay, $\mathrm{pH}, \mathrm{RIN}$, and $\mathrm{AD}$ ) revealed only an association between $\mathrm{pH}$ and $T N F \alpha$ expression levels
Table 3 Association analysis with CD68 glial marker.

\begin{tabular}{|c|c|c|}
\hline \multirow[b]{2}{*}{ SZ-C cohort } & \multicolumn{2}{|l|}{ CD68 } \\
\hline & $r$ & $\mathrm{n}$ \\
\hline$\overline{\text { CSF1R }}$ & $0.902^{a}$ & 26 \\
\hline$T L R 4$ & $0.543^{b}$ & 25 \\
\hline IL6 & $0.691^{a}$ & 27 \\
\hline$T N F \alpha$ & $0.812^{a}$ & 18 \\
\hline TNFRSF1A & $0.752^{a}$ & 25 \\
\hline IL10 & $0.819^{a}$ & 23 \\
\hline IL10RA & $0.723^{a}$ & 23 \\
\hline IL10RB & $0.653^{a}$ & 26 \\
\hline
\end{tabular}

$r$, Spearman's correlation. Significant associations are indicated in bold.

${ }^{a} p<0.001$.

${ }^{b} p<0.01$.

(Spearman $r=0.590, p=0.010$; Table 4). Linear regression analysis revealed that $T N F \alpha$ remained significant after adjusting for $\mathrm{pH}\left(\beta=-0.280, p=0.030\right.$, adjusted $\left.R^{2}=0.903\right)$. The schizophrenia subgroup analysis showed that daily antipsychotic dose, type of antipsychotic drug (second generation vs. first generation), age of onset and duration of the illness had no effect on gene expression levels for any of the genes altered in the study (Table 4).

Since we were performing multiple comparisons, we corrected the $p$-values obtained in the control-schizophrenia comparisons for a False Discovery Rate (FDR) of 0.1. All the significant $p$-values observed in our analyses (Figs. 1-4) were maintained after correction for an FDR of 0.1 (Table S2). In addition, we also corrected $p$-values for multiple comparisons of the association analysis with glia markers. All the significant $p$-values observed in the correlations were maintained after correction (Table S3).

\section{Discussion}

A dysfunction of the immune system/neuroinflammatory pathways has been linked to SZ (Gibney and Drexhage, 2013; Kirkpatrick and Miller, 2013). In this study, we have characterized the gene expression of a group of 21 key genes involved in immune homeostasis, including pro- and antiinflammatory cytokines, cytokine modulators (toll-like receptors, colony-stimulating factors, and members of the complement system) and glial markers in the prefrontal cortex in elderly chronic SZ. The present study reveals that the cytokine modulators CSF1R and TRL4, the proinflammatory cytokines IL6, TNF $\alpha$, and TNFRS1A, the antiinflammatory cytokines IL10, IL10RA, and ILIORB, and the glial marker CD68 are down-regulated in the dorsolateral prefrontal cortex in aged SZ patients. Moreover, we found that all the significantly down-regulated genes correlated with the expression levels of the glial marker CD68. Thus, this study reveals the alteration of several inflammatory/immune system markers in the dorsolateral prefrontal cortex in chronic SZ subjects at advanced age and suggests these changes may also be linked to the down-regulation of a marker for reactive microgliosis.

Cytokines are produced by various immune and nonimmune cells and include chemokines, interleukins, 


\section{Cytokines modulators}

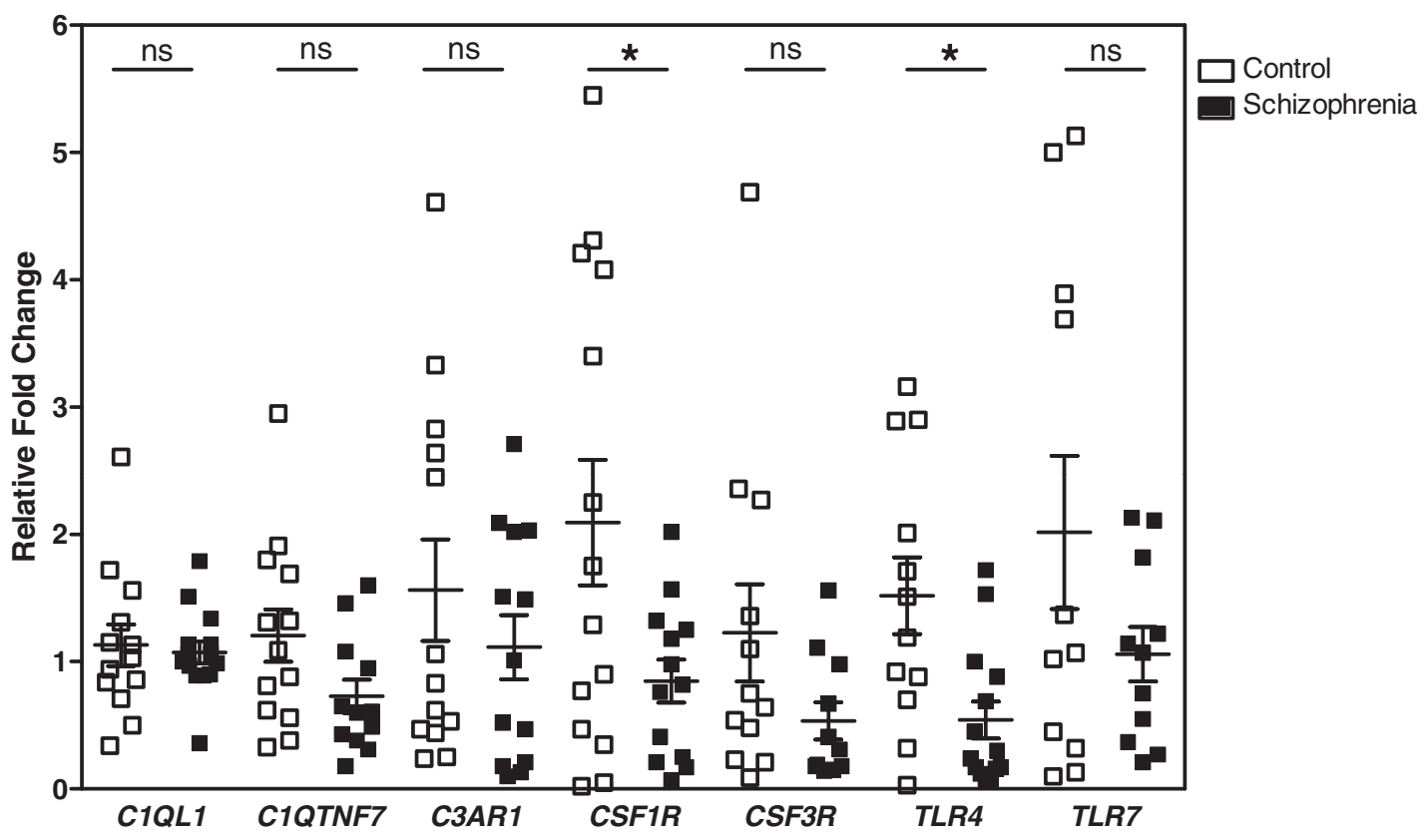

Fig. 1 mRNA expression levels of cytokine modulators in the dorsolateral prefrontal cortex in control and schizophrenia cases. Each individual value represents the mean of fold-change values for each subject for the distinct probes that were determined with TaqMan PCR assays and normalized to XPNPEP1. Mean and standard error of the mean is represented for each group. Mean fold-change values for each group were compared with Student's $t$-test (C1QTNF, C3AR1, CSF1R, TLR4, and TLR7) or Mann-Whitney $\mathrm{U}$ test (C1QL1 and CSF3R). One outlier for C1QL1, C3AR1, TLR4, and TLR7, and two outliers for CSF3R and C1QTNF7, were detected and were excluded from the analysis. One sample did not show detectable levels for C1QTNF7, C3AR1, and CSF1R and three samples did not show detectable levels for CSF3R and TLR7 in the SZ group. One sample did not show detectable levels for TLR4 and two samples did not show detectable levels for TLR7 in the control group. One sample for CSF3R was not included due to CT duplicate differences. Differences in schizophrenia cases versus control cases were considered statistically significant at $* p<0.05$. n.s, not significant.

interferons, lymphokines, and tumor necrosis factors. There is an increasing amount of evidence suggesting an immune system disruption in SZ. Several cytokines have been analysed in serum and/or plasma, and in post-mortem brain tissue of SZ patients. High blood and serum levels of proinflammatory cytokines have been reported in schizophrenia subjects (Kunz et al., 2011; Miller et al., 2011; Potvin et al., 2008; Xu et al., 1994); however, a goodly number of studies included middle-aged subjects with SZ, and little is known about possible deregulation of SZ in long-term treated elderly SZ subjects. In a meta-analysis, peripheral blood levels of IL $1 \beta$, IL6, and TGF $\beta$ were increased during an acute relapse and in patients with first-episode psychosis, suggesting that they might be state markers for acute exacerbations (Miller et al., 2011). In contrast to our results, the levels of the pro-inflammatory cytokines IL6,IL1 $\beta, I L 8$, and $T N F \alpha$ were found to be increased in the prefrontal cortex of middle-aged SZ patients (Fillman et al., 2013; Pandey et al., 2018), while we found IL6, TNF $\alpha$ and TNFRSF1A to be reduced in our elderly long-term treated sample. Moreover, increased levels of IL6 have been described in serum of elderly chronic SZ patients on stable antipsychotic medication, but with shorter duration of the illness (average 35 years) (Schmitt et al., 2005). Also increased levels of TLR4 RNA have been recently reported in the prefrontal cortex in a cohort of middle age cases of schizophrenia and schizoaf- fective cases (Volk et al., 2018). This result is the opposite of our finding and could be due to a different effect in middle age patients compared to elderly patients and also to different regulation of TLR4 expression in schizoaffective cases. Our results for TLR4 are in agreement with a recent post-mortem study in a similar, but not identical, cohort of elderly chronic schizophrenia patients, where TLR4 protein levels was also found to be down-regulated in the prefrontal cortex (MacDowell et al., 2017). This suggests that the changes in mRNA observed for pro-inflammatory cytokines could be the same at the protein level. Further studies will be needed to confirm this possibility. Our study supports an opposite deregulation for these mediators in patients with long disease duration and long-lasting treatments with antipsychotics at an advanced age. It is not clear how the advanced age and the long course of the disease of the cases could offset the initially active proinflammatory cytokine expression reported in other studies in middle-aged patients. However, long-term antipsychotic treatments could be responsible for this possible compensatory mechanism, resulting in down-regulation of the expression of these genes over the years of treatment. In this regard, normalization of increased cytokine levels has been reported in patients under stable antipsychotic treatment (Miller et al., 2011). This is in line with other studies that proposed that antipsychotics may exert anti-inflammatory 


\section{Pro-inflammatory cytokines}

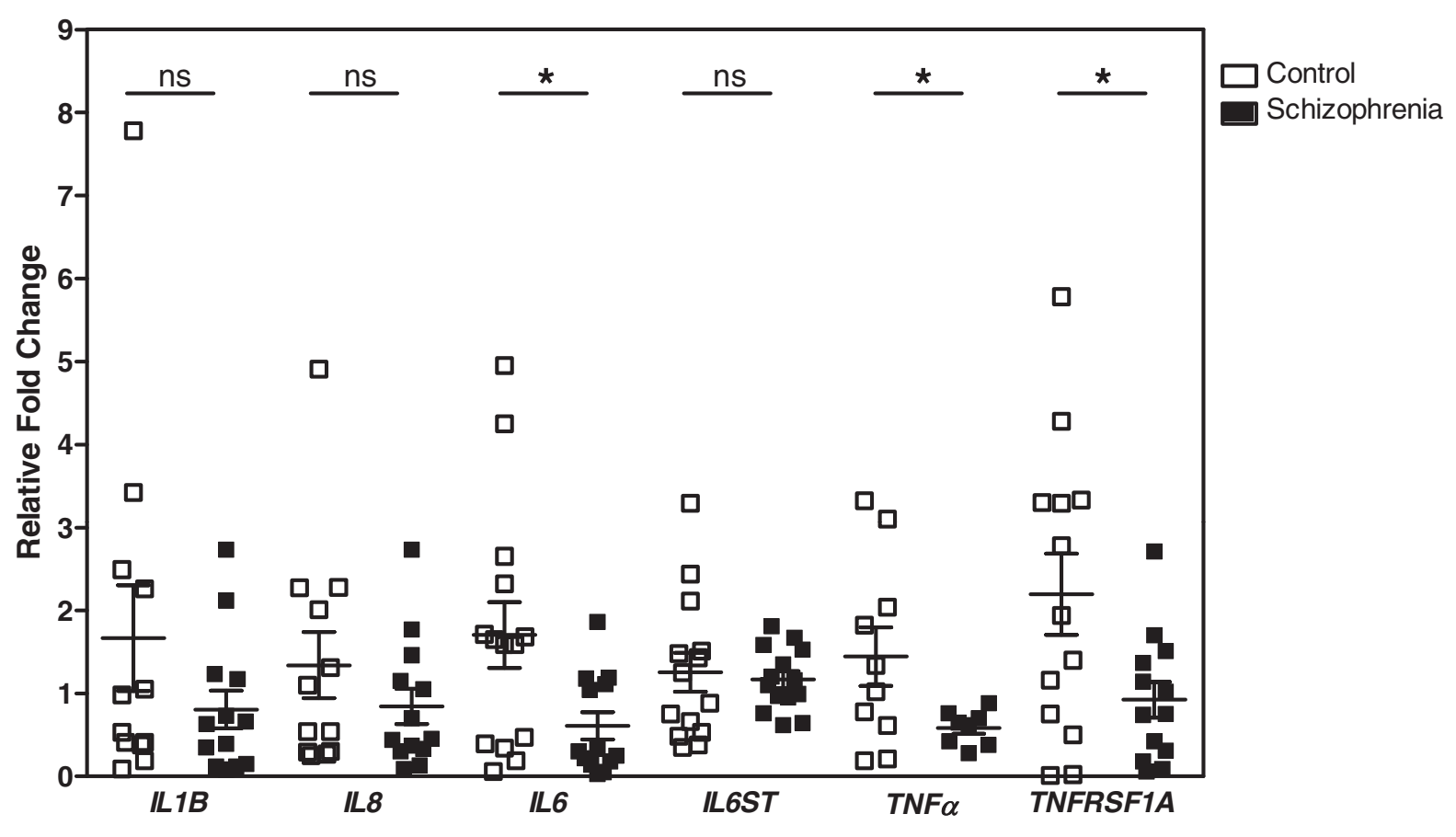

Fig. 2 mRNA expression levels of pro-inflammatory cytokines in the dorsolateral prefrontal cortex in control and schizophrenia cases. Each individual value represents the mean of fold-change values for each subject for the distinct probes that were determined with TaqMan PCR assays and normalized to XPNPEP1. Mean and standard error of the mean is represented for each group. Mean fold-change values for each group were compared with Student's $t$-test (IL8, IL6ST, TNF $\alpha$, and TNFRSF1A) or Mann-Whitney U test (IL1B and IL6). One outlier was detected for IL1B and TNFRSF1A and two outliers were detected for IL8 in the control group. In the SZ group, one outlier was detected for IL8, IL1B, and IL6. These outliers were not included in the analysis. One sample did not show detectable levels for TNFRSF1A in the SZ group, while four and six samples did not show detectable levels for TNF $\alpha$ in the case and control groups, respectively. Differences in schizophrenia cases versus control cases were considered statistically significant at * $p<0.05$. n.s, not significant.

effects (Müller, 2017; Tourjman et al., 2013). Although in our study in elderly patients we did not find an association between the last antipsychotic prescription and our molecular measures, the cases of this study were institutionalized patients under long-lasting antipsychotic medications with a high rate of treatment adherence. This raises the possibility that these treatments with antipsychotics over the years could be responsible for the down-regulation of pro-inflammatory cytokines observed in our study. It is also possible that the suicide component of the cohorts used in other studies might have contributed to the different results observed in this study. Our study included subjects that died of natural causes while other studies were carried out in cohorts that included subjects that committed suicide (Fillman et al., 2013; Pandey et al., 2018; Schmitt et al., 2005). Further studies in aged SZ patients are needed to investigate the influence of antipsychotics and the mechanism of death on the expression of immune and inflammatory mediators.

Our study also examined the anti-inflammatory cytokines IL10, IL10RA, IL10RB, TGFB1, and TGFB2 and found that the interleukin IL10 and its receptors IL1ORA and IL10RB were down-regulated in the dorsolateral prefrontal cortex in SZ subjects. An increase in IL10 in blood has been reported in first-episode psychosis (Goldsmith et al., 2016); however, a decrease in IL10 has also recently been reported in prefrontal cortex in schizophrenia (Pandey et al., 2018), while a recent meta-analysis also showed a decrease in blood IL10 in both acutely and chronically ill patients with schizophrenia (Goldsmith et al., 2016). Thus, our results in elderly patients seem to be in line with previous reports on this disorder with younger cohorts, in which an initial up-regulation of the anti-inflammatory cytokine IL10 in the disorder seems to be followed by a later down-regulation in the periphery and also in the brain.

Our results for microglial markers indicate that there is a decrease in the expression of the CD68 gene in the dorsolateral prefrontal cortex in elderly SZ subjects, which positively correlated with the altered cytokines and their modulators. This is in line with a previous post-mortem study that showed a correlation between the stage of activation of microglia and the expression levels of the pro-inflammatory cytokine $I L 1 B$ in the same region in middle-aged patients with schizophrenia (Fillman et al., 2013). The reduction observed in CD68 could be due to the long-lasting antipsychotic treatments of these patients, since a decrease in this marker has recently been reported in monocytes upon treatment with antipsychotics (Bahramabadi et al., 2017). Alternatively, the reduction observed could be the result of a lower density of microglia in tissue in these patients. 


\section{Anti-inflammatory cytokines}

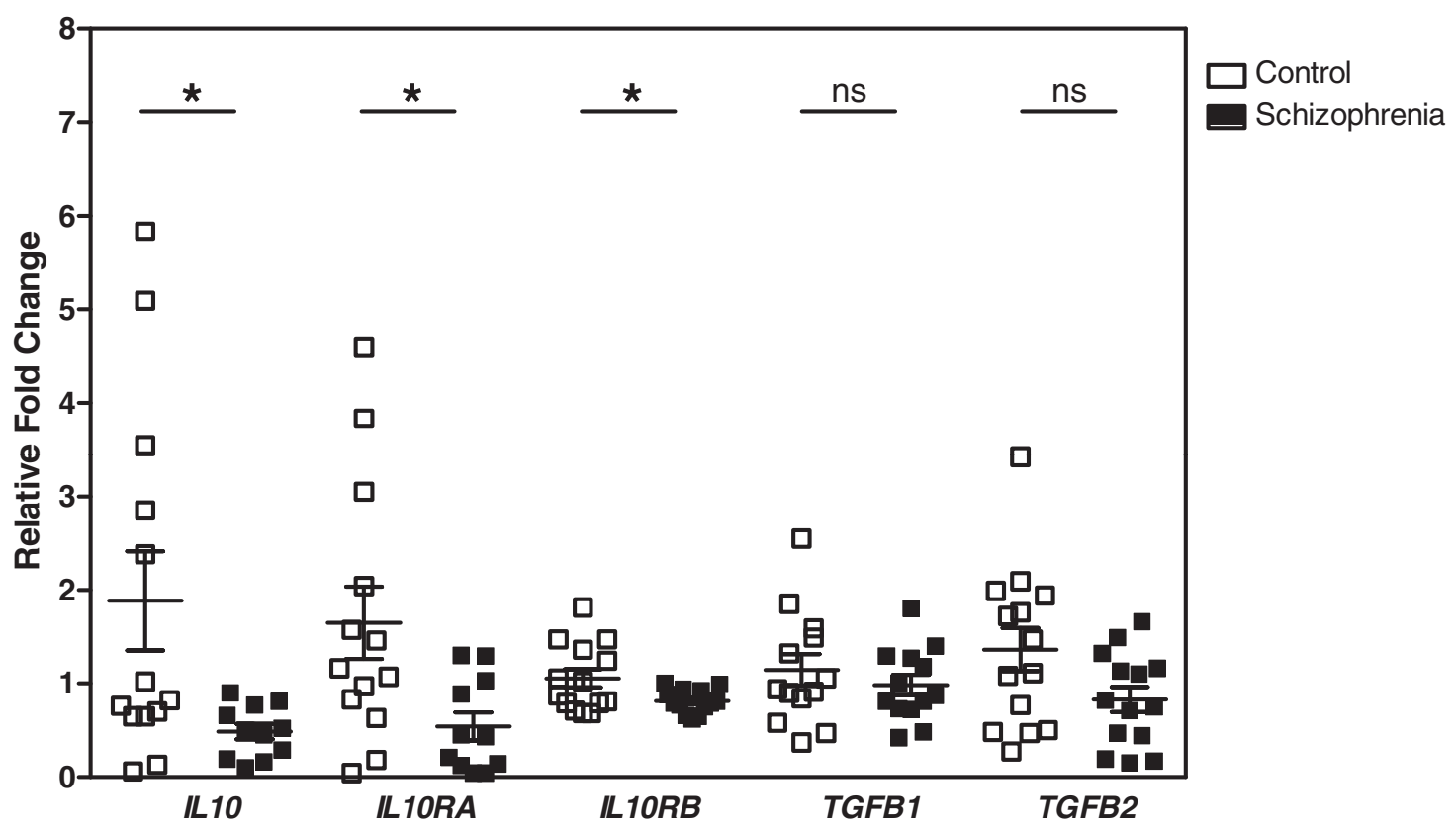

Fig. 3 mRNA expression levels of anti-inflammatory cytokines in the dorsolateral prefrontal cortex in control and schizophrenia cases. Each individual value represents the mean of fold-change values for each subject for the distinct probes that were determined with TaqMan PCR assays and normalized to XPNPEP1. Mean and standard error of the mean is represented for each group. Mean fold-change values for each group were compared with Student's $t$-test. One outlier was detected in the control group for TGFB1 and in the SZ group for IL10, TGFB1, IL10RA, and IL10RB, and these were not included in the analysis. One and two samples did not show detectable levels for IL1ORA and IL10 in the control and case groups, respectively. Differences in schizophrenia cases versus control cases were considered statistically significant at * $p<0.05$.; n.s, not significant.

\section{Glial markers}

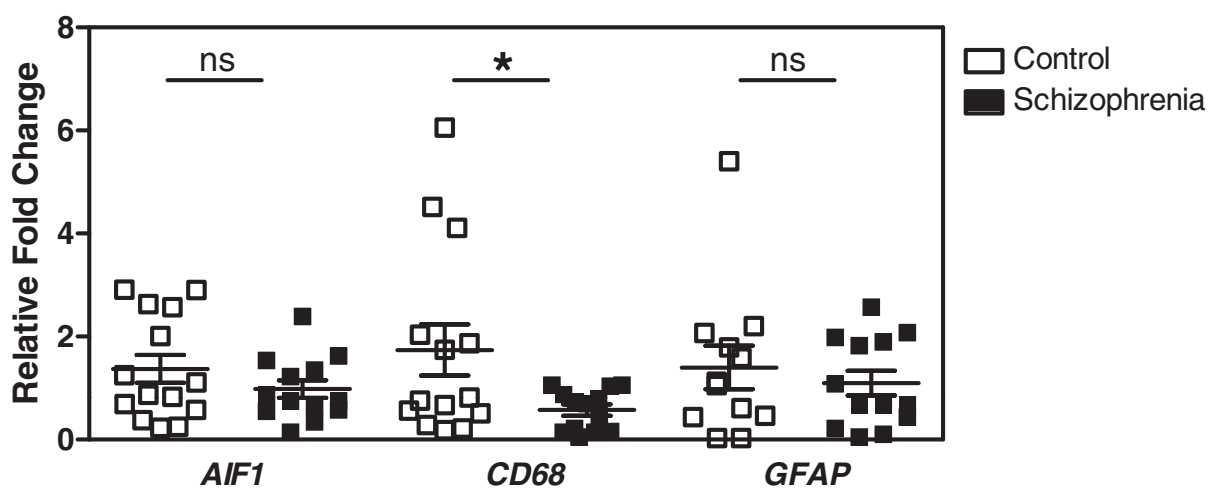

Fig. 4 mRNA expression levels of glial markers in the dorsolateral prefrontal cortex in control and schizophrenia cases. Each individual value represents the mean of the expression gene values for each subject for the distinct probes that were determined with TaqMan PCR assays and normalized to XPNPEP1. Mean and standard error of the mean is represented for each group. Mean fold-change values for each group were compared with Student's $t$-test (CD68 and AIF1) or Mann-Whitney U test (GFAP). One sample in the SZ group did not show detectable levels for the 3 genes. Two outliers were detected in the control group for GFAP and were not included in the analysis. Differences in schizophrenia cases versus control cases were considered statistically significant at * $p<0.05$. n.s, not significant.

However, the AIF1 gene expression (a pan-microglia maker) was not altered in our study, suggesting that a global reduction of microglia may not be occurring in the DLPFC in elderly schizophrenia. CD68 gene encodes for a lysosomal protein which is up-regulated in actively phagocytic microglia
(Zotova et al., 2013), raising the possibility that there might be a reduction in the more phagocytically active microglia subpopulation in these patients. Microglial activation and an increase in microglial cells in the brain of SZ patients have been reported in mostly chronic middle-age post-mortem 
Table 4 Association analysis of other variables in the study.

SZ-C cohort

\begin{tabular}{|c|c|c|c|c|c|c|}
\hline & $n$ & Age & PMD & $\mathrm{pH}$ & RIN & $A D$ \\
\hline$\overline{\text { CSF1R }}$ & 27 & $-0.053^{a}$ & $0.024^{a}$ & $0.254^{a}$ & $-0.033^{a}$ & $0.074^{a}$ \\
\hline TLR4 & 26 & $-0.082^{b}$ & $0.255^{b}$ & -0.109 & $-0.030^{b}$ & $0,014^{\mathrm{b}}$ \\
\hline IL6 & 27 & $-0.168^{a}$ & $0.058^{\mathrm{a}}$ & $0.276^{a}$ & $0.157^{a}$ & $-0.071^{a}$ \\
\hline$T N F \alpha$ & 18 & $0.017^{a}$ & $-0.002^{a}$ & $0.590^{\mathrm{a}}$ & $-0.060^{\mathrm{a}}$ & $0.120^{a}$ \\
\hline TNFRSF1A & 26 & $0.092^{a}$ & $0.070^{a}$ & $0.128^{a}$ & $0.019^{a}$ & $-0.081^{a}$ \\
\hline IL10 & 24 & $-0.001^{\mathrm{a}}$ & $0.043^{a}$ & $0.394^{\mathrm{a}}$ & $0.011^{a}$ & $0.242^{\mathrm{a}}$ \\
\hline IL10RA & 24 & $0.195^{a}$ & $0.132^{\mathrm{a}}$ & $0.193^{a}$ & $0.299^{a}$ & $0.174^{a}$ \\
\hline IL10RB & 27 & $-0.111^{\mathrm{a}}$ & $0.209^{a}$ & $-0.053^{a}$ & $-0.224^{a}$ & $0.350^{\mathrm{a}}$ \\
\hline CD68 & 27 & $-0.191^{\mathrm{a}}$ & $0.126^{a}$ & $0.170^{\mathrm{a}}$ & $0.030^{\mathrm{a}}$ & $-0.020^{\mathrm{a}}$ \\
\hline
\end{tabular}

SZ cohort

\begin{tabular}{lllll}
\hline & $\mathrm{n}$ & Daily AP dose & Age of Onset & Duration of illness \\
\hline CSF1R & 13 & $0.323^{\mathrm{b}}$ & $-0.215^{\mathrm{a}}$ & $0.165^{\mathrm{b}}$ \\
TLR4 & 14 & $0.345^{\mathrm{b}}$ & $-0.006^{\mathrm{a}}$ & $0.102^{\mathrm{b}}$ \\
IL6 & 13 & $0.156^{\mathrm{b}}$ & $-0.061^{\mathrm{a}}$ & $-0.104^{\mathrm{b}}$ \\
TNF $\alpha$ & 8 & $-0.040^{\mathrm{b}}$ & $0.024^{\mathrm{a}}$ & $-0.290^{\mathrm{b}}$ \\
TNFRSF1A & 13 & $0.048^{\mathrm{b}}$ & $0.173^{\mathrm{a}}$ & $0.232^{\mathrm{b}}$ \\
IL10 & 11 & $0.088^{\mathrm{b}}$ & $-0.200^{\mathrm{a}}$ & $0.273^{\mathrm{b}}$ \\
IL10RA & 11 & $-0.101^{\mathrm{b}}$ & $0.317^{\mathrm{a}}$ & $0.127^{\mathrm{b}}$ \\
IL10RB & 13 & $0.392^{\mathrm{b}}$ & $-0.437^{\mathrm{a}}$ & $0.330^{\mathrm{b}}$ \\
CD68 & 13 & $0.345^{\mathrm{b}}$ & $-0.291^{\mathrm{a}}$ & $-0.254^{\mathrm{b}}$
\end{tabular}

a Spearman's correlation for non-parametric variables;

b Pearson's $r$ for parametric variables; PMD, post-mortem delay; RIN, RNA integrity number; AP, antipsychotic; AD, histological stage of Alzheimer disease as described previously (Braak et al., 2006; Braak and Braak, 1991). Significant associations $(p<0.05)$ are indicated in bold.

$¥$ Last chlorpromazine equivalent dose was calculated based on the electronic records of drug prescriptions of the patients. Comparison of mRNA levels was performed between patients under first-generation and second-generation antipsychotic medication with the exception of IL10 and IL1ORB, for which there were not enough determinations for this analysis. No significant differences were found (data not shown).

studies (Bayer et al., 1999; Busse et al., 2012; Radewicz et al., 2000; van Kesteren et al., 2017; Wierzba-Bobrowicz et al., 2005). This process has been reported to be influenced by some clinical features and by the mechanism of death (Laskaris et al., 2016). One study found an increase in microglial density in middle-aged patients with paranoid schizophrenia versus non-acute schizophrenia patients (Busse et al., 2012). Increased microglial density could also be the result of a violent death of the patients, since an increased number of activated microglia in the dorsolateral prefrontal cortex has been reported in patients who committed suicide during acute psychosis (Busse et al., 2012; Steiner et al., 2008, 2006). However, the patients included in our study were mainly non-acute schizophrenia patients who died of natural causes; thus an increased activation of microglia seems unlikely in these patients.

Although neuroinflammation is characterized by the activation of microglial cells, astrocytes also play an important role (Chavarria and Alcocer-Varela, 2004). Expression levels for the astrocyte marker GFAP did not differ among the groups in our study, although previous studies have reported a decrease or no change in GFAP mRNA expression (Barley et al., 2009; Katsel et al., 2011; Trépanier et al., 2016; Webster et al., 2005). A similar situation also occurred with GFAP protein; studies have reported decreased, similar, or increased levels in schizophrenia patients depending on the brain region examined (Arnold et al., 1996; Steffek et al., 2008; Toro et al., 2006; Trépanier et al., 2016). A recent study found evidence of astrogliosis (mRNA and protein) in a subset of patients with schizophrenia and high expression of inflammatory markers (Catts et al., 2014), suggesting that the differences in previous studies were due to cohort differences in illness stage, exposure to treatment, or a failure to consider subsets of subjects with SZ.

The use of human post-mortem tissue allows for the molecular dissection of possible disrupted pathways in psychiatric disorders, but it presents limitations that have to be considered. First, the potential effect of possible confounding factors, including age, gender, post-mortem delay, histological degree of Alzheimer's disease, $\mathrm{pH}$, and RIN has to be carefully explored. These factors have been controlled for and their potential influence ruled out in our study. Second, the patients included in our study were taking longlasting and heterogeneous antipsychotic medications. To control for this variable, we used the last daily chlorpromazine equivalent dose, calculated as reported previously (Gardner et al., 2010), in a bivariate analysis (Table 4). The last daily chlorpromazine equivalent dose had no effect on the variables studied here (Table 4). We also searched for differences in our molecular measures between patients under first and second generation antipsychotics. We did not find any differences between the two groups. However, larger sample size is required to increase the statistical power of those analyses. Third, since some of the 
pro-inflammatory cytokines in this study (IL6, IL1B) have been previously described as increased in frontal cortex of AD grade I and II (López-González, I. et al., 2015b), initial histological stages of Alzheimer disease (AD) might also have influenced our results. Here we report down-regulation of IL-6 instead of the increase reported in low degree AD. Our group of cases was matched with a control group also taking into account the histological degree of $A D(0-$ III, low degree). In addition, no associations were found between histological $A D$ stage and our molecular measures (data notshown). Fourth, the study only included men. Fifth, a careful interpretation should be made of the negative results of our study, which could be the result of limited statistical power rather than the lack of alteration in schizophrenia. Sixth, institutionalization of cases could have also influenced our findings. Therefore, further studies with larger cohorts of aged subjects with equal representation of both genders, and, if possible, non-institutionalized, drug naïve patients would be of interest. Despite these limitations, the findings from this study may contribute towards better understanding of the role of the immune/inflammatory systems in schizophrenia at an advanced age.

Taken together, our findings show a decrease in the expression of cytokine and inflammation mediators in the dorsolateral prefrontal cortex of subjects with elderly chronic SZ. Thus, the results reported here further suggest that a dysfunction of the immune system/neuroinflammation pathways is possibly linked with the abundance of active microglia that may be contributing to mechanisms that are altered in the dorsolateral prefrontal cortex in an elderly population with chronic SZ.

\section{Role of funding source}

This work was supported by CIBERNED to IF and a Miguel Servet grant (MS16/00153-CP16/00153) to BR financed and integrated into the National $R+D+I$ and funded by the Instituto de Salud Carlos III (Spanish Ministry of Health) - General Branch Evaluation and Promotion of Health Research - and the European Regional Development Fund (ERDF). The funding bodies had no further role in study design; in the collection, analysis and interpretation of data; in the writing of the report; and in the decision to submit the paper for publication.

\section{Contributors}

Author I.L-G.: sample analysis, statistical analysis, interpretation of data and co-writing of the first draft of the manuscript. Author R.P.: sample preparation, statistical analysis, interpretation of data and co-writing of the first draft of the manuscript. Author E.V.: statistical analysis, interpretation of data and participated in the article preparation. Author A.E.:implemented the clinical protocol. Author I.F.: conception and designed of the molecular study and interpretation of data and co-wrote the first draft of the manuscript. Author B.R.: design of the molecular study, analysis and interpretation of data; and co-wrote the first draft of the manuscript. All authors revised the manuscript critically and approved the final article.

\section{Conflict of Interest}

All authors declare that they have no financial conflicts of interest.

\section{Acknowledgments}

We thank Dr. Rose for the English editing of this manuscript. The authors thank the donors and their families for the donation of their brains; the collaboration of the team of the Hospital Universitari de Bellvitge Brain Bank, and the team of the Banc de Teixits Neurologics of Parc Sanitari Sant Joan de Déu for their help.

\section{Supplementary material}

Supplementary material associated with this article can be found, in the online version, at doi:10.1016/j.euroneuro. 2018.12.011.

\section{References}

Andersen, C.L., Jensen, J.L., Ørntoft, T.F., 2004. Normalization of real-time quantitative reverse transcription-PCR data: a model-based variance estimation approach to identify genes suited for normalization, applied to bladder and colon cancer data sets. Cancer Res. 64, 5245-5250. doi:10.1158/0008-5472. CAN-04-0496.

Arnold, S.E., Franz, B.R., Trojanowski, J.Q., Moberg, P.J., Gur, R.E., 1996. Glial fibrillary acidic protein-immunoreactive astrocytosis in elderly patients with schizophrenia and dementia. Acta Neuropathol. 91, 269-277. doi:10.1007/s004010050425.

Arnold, S.E., Trojanowski, J.Q., Gur, R.E., Blackwell, P., Han, L.Y., Choi, C., 1998. Absence of neurodegeneration and neural injury in the cerebral cortex in a sample of elderly patients with schizophrenia. Arch. Gen. Psychiatry 55, 225-232. doi:10.1001/ archpsyc.55.3.225.

Bahramabadi, R., Samadi, M., Vakilian, A., Jafari, E., Fathollahi, M.S., Arababadi, M.K., 2017. Evaluation of the effects of anti-psychotic drugs on the expression of CD68 on the peripheral blood monocytes of Alzheimer patients with psychotic symptoms. Life Sci. 179, 73-79. doi:10.1016/j.lfs.2017.04.024.

Barley, K., Dracheva, S., Byne, W., 2009. Subcortical oligodendrocyte- and astrocyte-associated gene expression in subjects with schizophrenia, major depression and bipolar disorder. Schizophr. Res. 112, 54-64. doi:10.1016/j.schres.2009.04.019.

Barrachina, M., Castaño, E., Ferrer, I., 2006. TaqMan PCR assay in the control of RNA normalization in human post-mortem brain tissue. Neurochem. Int. 49, 276-284. doi:10.1016/j.neuint. 2006.01.018.

Bayer, T.A., Buslei, R., Havas, L., Falkai, P., 1999. Evidence for activation of microglia in patients with psychiatric illnesses. Neurosci. Lett. 271, 126-128. doi:10.1016/S0304-3940(99)00545-5.

Benjamini, Y., Hochberg, Y., 1995. Controlling the false discovery rate: a practical and powerful approach to multiple testing. Source J. R. Stat. Soc. Ser. B 57, 289-300.

Bora, E., Murray, R.M., 2014. Meta-analysis of cognitive deficits in ultra-high risk to psychosis and first-episode psychosis: do the 
cognitive deficits progress over, or after, the onset of psychosis? Schizophr. Bull. 40, 744-755. doi:10.1093/schbul/sbt085.

Braak, H., Alafuzoff, I., Arzberger, T., Kretzschmar, H., Del Tredici, K., 2006. Staging of Alzheimer disease-associated neurofibrillary pathology using paraffin sections and immunocytochemistry. Acta Neuropathol. 112, 389-404. doi:10.1007/ s00401-006-0127-z.

Braak, H., Braak, E., 1991. Neuropathological stageing of Alzheimer-related changes. Acta Neuropathol. 82, 239-259. doi:10.1007/BF00308809.

Brown, A.S., 2011. Exposure to prenatal infection and risk of schizophrenia. Front. Psychiatry 2, 63. doi:10.3389/fpsyt.2011. 00063.

Brown, A.S., Begg, M.D., Gravenstein, S., Schaefer, C.A., Wyatt, R.J., Bresnahan, M., Babulas, V.P., Susser, E.S., 2004. Serologic evidence of prenatal influenza in the etiology of schizophrenia. Arch. Gen. Psychiatry 61, 774. doi:10.1001/ archpsyc.61.8.774.

Brown, A.S., Derkits, E.J., 2010. Prenatal infection and schizophrenia: a review of epidemiologic and translational studies. Am. J. Psychiatry 167, 261-280. doi:10.1176/appi.ajp.2009.09030361.

Busse, S., Busse, M., Schiltz, K., Bielau, H., Gos, T., Brisch, R., Mawrin, C., Schmitt, A., Jordan, W., Müller, U.J., Bernstein, H.G., Bogerts, B., Steiner, J., 2012. Different distribution patterns of lymphocytes and microglia in the hippocampus of patients with residual versus paranoid schizophrenia: further evidence for disease course-related immune alterations? Brain. Behav. Immun. 26, 1273-1279. doi:10.1016/J.BBI.2012.08.005.

Cagnin, A., Brooks, D.J., Kennedy, A.M., Gunn, R.N., Myers, R., Turkheimer, F.E., Jones, T., Banati, R.B., 2001. In-vivo measurement of activated microglia in dementia. Lancet 358, 461-467. doi:10.1016/S0140-6736(01)05625-2.

Canuti, M., Buka, S., Jazaeri Farsani, S.M., Oude Munnink, B.B., Jebbink, M.F., van Beveren, N.J.M., de Haan, L., Goldstein, J., Seidman, L.J., Tsuang, M.T., Storosum, J.G., van der Hoek, L., 2015. Reduced maternal levels of common viruses during pregnancy predict offspring psychosis: potential role of enhanced maternal immune activity? Schizophr. Res. 166, 248-254. doi:10. 1016/j.schres.2015.04.037.

Catts, V.S., Wong, J., Fillman, S.G., Fung, S.J., Shannon Weickert, C., 2014. Increased expression of astrocyte markers in schizophrenia: association with neuroinflammation. Aust. New Zeal. J. Psychiatry 48, 722-734. doi:10.1177/ 0004867414531078.

Chavarria, A., Alcocer-Varela, J., 2004. Is damage in central nervous system due to inflammation? Autoimmun. Rev. 3, 251-260. doi:10.1016/j.autrev.2003.09.006.

Colleste, K., Plavén Sigray, P., Fatouros-Bergman, H., Victorsson, P., Schain, M., Forsberg, A., Amini, N., Aeinehband, S., Karolinska Schizophrenia Project (KaSP) consortium, Erhardt, S., Halldin, C., Flyckt, L., Farde, L., Cervenka, S., 2017. Lower levels of the glial cell marker TSPO in drug-naive first-episode psychosis patients as measured using PET and [11C] PBR28. Mol. Psychiatry 6, 850-856. doi:10.1038/mp.2016.247.

Coughlin, J.M, Wang, Y., Ambinder, E.B., Ward, R.E., Minn, I., Vranesic, M., Kim, P.K., Ford, C.N., Higgs, C., Hayes, L.N., Schretlen, D.J., Dannals, R.F., Kassiou, M., Sawa, A., Pomper, M.G., 2016. In vivo markers of inflammatory response in recent-onset schizophrenia: a combined study using [(11)C]DPA713 PET and analysis of CSF and plasma. Transl. Psychiatry 6, e777. doi:10.1038/tp.2016.40.

Doorduin, J., de Vries, E.F.J., Willemsen, A.T.M., de Groot, J.C., Dierckx, R.A., Klein, H.C., 2009. Neuroinflammation in schizophrenia-related psychosis: a PET study. J. Nucl. Med. 50, 1801-1807. doi:10.2967/jnumed.109.066647.

Durrenberger, P.F., Fernando, F.S., Magliozzi, R., Kashefi, S.N., Bonnert, T.P., Ferrer, I., Seilhean, D., Nait-Oumesmar, B., Schmitt, A., Gebicke-Haerter, P.J., Falkai, P., Grünblatt, E.,
Palkovits, M., Parchi, P., Capellari, S., Arzberger, T., Kretzschmar, H., Roncaroli, F., Dexter, D.T., Reynolds, R., 2012. Selection of novel reference genes for use in the human central nervous system: a BrainNet Europe Study. Acta Neuropathol. 124, 893-903. doi:10.1007/s00401-012-1027-z.

Fillman, S.G., Cloonan, N., Catts, V.S., Miller, L.C., Wong, J., McCrossin, T., Cairns, M., Weickert, C.S., 2013. Increased inflammatory markers identified in the dorsolateral prefrontal cortex of individuals with schizophrenia. Mol. Psychiatry 18, 206-214. doi: $10.1038 / \mathrm{mp} .2012 .110$.

Foussias, G., Siddiqui, I., Fervaha, G., Agid, O., Remington, G., 2015. Dissecting negative symptoms in schizophrenia: opportunities for translation into new treatments. J. Psychopharmacol. 29, 116-126. doi:10.1177/0269881114562092.

Garcia-Esparcia, P., Llorens, F., Carmona, M., Ferrer, I., 2014. Complex deregulation and expression of cytokines and mediators of the immune response in parkinson's disease brain is region dependent. Brain Pathol. 24, 584-598. doi:10.1111/bpa.12137.

Gardner, D.M., Murphy, A.L., O’Donnell, H., Centorrino, F., Baldessarini, R.J., 2010. International consensus study of antipsychotic dosing. Am. J. Psychiatry 167, 686-693. doi:10.1176/ appi.ajp.2009.09060802.

Gibney, S.M., Drexhage, H.A., 2013. Evidence for a dysregulated immune system in the etiology of psychiatric disorders. J. Neuroimmune Pharmacol. 8, 900-920. doi:10.1007/ s11481-013-9462-8.

Gilmore, J.H., Jarskog, L.F., 1997. Exposure to infection and brain development: cytokines in the pathogenesis of schizophrenia. Schizophr. Res. 24, 365-367. doi:10.1016/S0920-9964(96) 00123-5.

Goldsmith, D.R., Rapaport, M.H., Miller, B.J., 2016. A meta-analysis of blood cytokine network alterations in psychiatric patients: comparisons between schizophrenia, bipolar disorder and depression. Mol. Psychiatry 21, 1696-1709. doi:10.1038/mp.2016. 3.

Hafizi, S., Da Silva, T., Gerritsen, C., Kiang, M., Bagby, R.M., Prce, I., Wilson, A.A., Houle, S., Rusjan, P.M., Mizrahi, R., 2017. Imaging microglial activation in individuals at clinical high risk for psychosis: an in vivo PET study with [18F]FEPPA. Neuropsychopharmacology 13, 2474-2481. doi:10.1038/npp.2017.111.

Kato, T.A., Monji, A., Mizoguchi, Y., Hashioka, S., Horikawa, H., Seki, Y., Kasai, M., Utsumi, H., Kanba, S., 2011. AntiInflammatory properties of antipsychotics via microglia modulations: are antipsychotics a "fire extinguisher" in the brain of schizophrenia? Mini Rev. Med. Chem. 11, 565-574. doi:10.2174/ 138955711795906941.

Katsel, P., Byne, W., Roussos, P., Tan, W., Siever, L., Haroutunian, V., 2011. Astrocyte and glutamate markers in the superficial, deep, and white matter layers of the anterior cingulate gyrus in schizophrenia. Neuropsychopharmacology 36, 1171-1177. doi:10.1038/npp.2010.252.

Kenk, M., Selvanathan, T., Rao, N., Suridjan, I., Rusjan, P., Remington, G., Meyer, J.H., Wilson, A.A., Houle, S., Mizrahi, R., 2015. Imaging neuroinflammation in gray and white matter in schizophrenia: an in-vivo PET study with [18F]-FEPPA. Schizophr. Bull. 1, 85-93. doi:10.1093/schbul/sbu157.

Khandaker, G.M., Zimbron, J., Lewis, G., Jones, P.B., 2013. Prenatal maternal infection, neurodevelopment and adult schizophrenia: a systematic review of population-based studies. Psychol. Med. 43, 239-257. doi:10.1017/S0033291712000736.

Kirkpatrick, B., Miller, B.J., 2013. Inflammation and schizophrenia. Schizophr. Bull. 39, 1174-1179. doi:10.1093/schbul/sbt141.

Kunz, M., Ceresér, K.M., Goi, P.D., Fries, G.R., Teixeira, A.L., Fernandes, B.S., Belmonte-de-Abreu, P.S., Kauer-Sant'Anna, M., Kapczinski, F., Gama, C.S., 2011. Serum levels of IL-6, IL-10 and TNF- $\alpha$ in patients with bipolar disorder and schizophrenia: differences in pro- and anti-inflammatory balance. Rev. Bras. Psiquiatr. 33, 268-274. doi:10.1590/S1516-44462011000300010. 
Laskaris, L.E., Di Biase, M.A., Everall, I., Chana, G., Christopoulos, A., Skafidas, E., Cropley, V.L., Pantelis, C., 2016. Microglial activation and progressive brain changes in schizophrenia. Br. J. Pharmacol. 173, 666-680. doi:10.1111/bph.13364.

Llorens, F., López-González, I., Thüne, K., Carmona, M., Zafar, S., Andréoletti, O., Zerr, I., Ferrer, I., 2014. Subtype and regionalspecific neuroinflammation in sporadic Creutzfeldt-Jakob disease. Front. Aging Neurosci. 6, 198. doi:10.3389/fnagi.2014. 00198.

López-González, I., Aso, E., Carmona, M., Armand-Ugon, M., Blanco, R., Naudí, A., Cabré, R., Portero-Otin, M., Pamplona, R., Ferrer, I., 2015a. Neuroinflammatory gene regulation, mitochondrial function, oxidative stress, and brain lipid modifications with disease progression in Tau P301S transgenic mice as a model of frontotemporal lobar degeneration-Tau. J. Neuropathol. Exp. Neurol. 74, 975-999. doi:10.1097/NEN. 0000000000000241.

López-González, I., Schlüter, A., Aso, E., Garcia-Esparcia, P., Ansoleaga, B., LLorens, F., Carmona, M., Moreno, J., Fuso, A., Portero-Otin, M., Pamplona, R., Pujol, A., Ferrer, I., 2015b. Neuroinflammatory signals in alzheimer disease and APP/PS1 transgenic mice. J. Neuropathol. Exp. Neurol. 74, 319-344. doi:10.1097/NEN.0000000000000176.

López González, I., Garcia-Esparcia, P., Llorens, F., Ferrer, I., 2016. Genetic and transcriptomic profiles of inflammation in neurodegenerative diseases: Alzheimer, Parkinson, CreutzfeldtJakob and Tauopathies. Int. J. Mol. Sci. 17, 206. doi:10.3390/ ijms17020206.

MacDowell, K.S., Pinacho, R., Leza, J.C., Costa, J., Ramos, B., García-Bueno, B., 2017. Differential regulation of the TLR4 signalling pathway in post-mortem prefrontal cortex and cerebellum in chronic schizophrenia: Relationship with SP transcription factors. Prog. Neuro Psychopharmacol. Biol. Psychiatry 79, 481492. doi:10.1016/j.pnpbp.2017.08.005.

Meyer, U., 2013. Developmental neuroinflammation and schizophrenia. Prog. Neuro Psychopharmacol. Biol. Psychiatry 42, 20-34. doi:10.1016/j.pnpbp.2011.11.003.

Meyronet, D., Dorey, A., Massoma, P., Rey, C., Alix, E., Silva, K., Perrin, C., Quadrio, I., Perret-Liaudet, A., Streichenberger, N., Thomasset, N., Honnorat, J., Arzberger, T., Kretzschmar, H., 2015. The workflow from post-mortem human brain sampling to cell microdissection: a Brain Net Europe study. J. Neural Transm. 122, 975-991 doi:10.1007/s00702-015-1378-4.

Miller, B.J., Buckley, P., Seabolt, W., Mellor, A., Kirkpatrick, B., 2011. Meta-analysis of cytokine alterations in schizophrenia: clinical status and antipsychotic effects. Biol. Psychiatry 70, 663-671. doi:10.1016/j.biopsych.2011.04.013

Monji, A., Kato, T.A., Mizoguchi, Y., Horikawa, H., Seki, Y., Kasai, M., Yamauchi, Y., Yamada, S., Kanba, S., 2013. Neuroinflammation in schizophrenia especially focused on the role of microglia. Prog. Neuro Psychopharmacol. Biol. Psychiatry 42, 115-121. doi:10.1016/j.pnpbp.2011.12.002.

Monji, A., Kato, T., Kanba, S., 2009. Cytokines and schizophrenia: microglia hypothesis of schizophrenia. Psychiatry Clin. Neurosci. 63, 257-265.

Müller, N., 2017. Immunological aspects of the treatment of depression and schizophrenia. Dialogues Clin. Neurosci. 19, 55-63.

Müller, N., Weidinger, E., Leitner, B., Schwarz, M.J., 2015. The role of inflammation in schizophrenia. Front. Neurosci. 9, 372. doi: 10.3389 /fnins. 2015.00372.

Pandey, G.N., Rizavi, H.S., Zhang, H., Ren, X., 2018. Abnormal gene and protein expression of inflammatory cytokines in the postmortem brain of schizophrenia patients. Schizophr. Res. 192, 247-254. doi:10.1016/j.schres.2017.04.043.

Potvin, S., Stip, E., Sepehry, A.A., Gendron, A., Bah, R., Kouassi, E., 2008. Inflammatory cytokine alterations in schizophrenia: a systematic quantitative review. Biol. Psychiatry 63, 801-808. doi:10.1016/j.biopsych.2007.09.024.
Radewicz, K., Garey, L.J., Gentleman, S.M., Reynolds, R., 2000. Increase in HLA-DR immunoreactive microglia in frontal and temporal cortex of chronic schizophrenics. J. Neuropathol. Exp. Neurol. 59, 137-150.

Ross, S.M., 2003. Peirce's criterion for the elimination of suspect experimental data. J. Eng. Technol. 20 (2), 1-12 http://classes.engineering.wustl.edu/2009/fall/che473/ handouts/OutlierRejection.pdf.

Sakurai, T., Gamo, N.J., Hikida, T., Kim, S.-H., Murai, T., Tomoda, T., Sawa, A., 2015. Converging models of schizophrenia - network alterations of prefrontal cortex underlying cognitive impairments. Prog. Neurobiol. 134, 178-201. doi:10.1016/ j.pneurobio.2015.09.010.

Sato-Kasai, M., Kato, T.A., Ohgidani, M., Mizoguchi, Y., Sagata, N., Inamine, S., Horikawa, H., Hayakawa, K., Shimokawa, N., Kyuragi, S., Seki, Y., Monji, A., Kanba, S., 2016. Aripiprazole inhibits polyl:C-induced microglial activation possibly via TRPM7. Schizophr. Res. 178, 35-43. doi:10.1016/j.schres.2016.08.022.

Schmitt, A., Bertsch, T., Tost, H., Bergmann, A., Henning, U., Klimke, A., Falkai, P., 2005. Increased serum interleukin-1 beta and interleukin- 6 in elderly, chronic schizophrenic patients on stable antipsychotic medication. Neuropsychiatr. Dis. Treat. 1, 171-177. doi:10.2147/nedt.1.2.171.61048.

Stahl, S.M., Buckley, P.F., 2007. Negative symptoms of schizophrenia: a problem that will not go away. Acta Psychiatr. Scand. 115, 4-11. doi:10.1111/j.1600-0447.2006.00947.x.

Steffek, A.E., McCullumsmith, R.E., Haroutunian, V., MeadorWoodruff, J.H., 2008. Cortical expression of glial fibrillary acidic protein and glutamine synthetase is decreased in schizophrenia. Schizophr. Res. 103, 71-82. doi:10.1016/j.schres. 2008.04.032.

Steiner, J., Bielau, H., Brisch, R., Danos, P., Ullrich, O., Mawrin, C., Bernstein, H.-G., Bogerts, B., 2008. Immunological aspects in the neurobiology of suicide: Elevated microglial density in schizophrenia and depression is associated with suicide. J. Psychiatr. Res. 42, 151-157. doi:10.1016/j.jpsychires.2006.10. 013

Steiner, J., Mawrin, C., Ziegeler, A., Bielau, H., Ullrich, O., Bernstein, H.-G., Bogerts, B., 2006. Distribution of HLA-DRpositive microglia in schizophrenia reflects impaired cerebral lateralization. Acta Neuropathol. 112, 305-316. doi:10.1007/ s00401-006-0090-8.

Teffer, K., Semendeferi, K., 2012. Human prefrontal cortex. Progress in Brain Research, pp. 191-218. doi:10.1016/ B978-0-444-53860-4.00009-X.

Toda, M., Abi-Dargham, A., 2007. Dopamine hypothesis of schizophrenia: making sense of it all. Curr. Psychiatry Rep. 9, 329-336. doi:10.1007/s11920-007-0041-7.

Toro, C.T., Hallak, J.E.C., Dunham, J.S., Deakin, J.F.W., 2006. Glial fibrillary acidic protein and glutamine synthetase in subregions of prefrontal cortex in schizophrenia and mood disorder. Neurosci. Lett. 404, 276-281. doi:10.1016/J.NEULET.2006.05.067.

Tourjman, V., Kouassi, É., Koué, M.-È., Rocchetti, M., FortinFournier, S., Fusar-Poli, P., Potvin, S., 2013. Antipsychotics' effects on blood levels of cytokines in schizophrenia: a metaanalysis. Schizophr. Res. 151, 43-47. doi:10.1016/j.schres.2013. 10.011.

Trépanier, M.O., Hopperton, K.E., Mizrahi, R., Mechawar, N., Bazinet, R.P., 2016. Postmortem evidence of cerebral inflammation in schizophrenia: a systematic review. Mol. Psychiatry 21, 1009-1026. doi:10.1038/mp.2016.90.

van Berckel, B.N, Bossong, M.G., Boellaard, R, Kloet, R., Schuitemaker, A., Caspers, E., Luurtsema, G., Windhorst, A.D., Cahn, W., Lammertsma, A.A., Kahn, R.S., 2008. Microglia activation in recent-onset schizophrenia: a quantitative (R)[11C]PK11195 positron emission tomography study. Biol. Psychiatry 9, 820-822. doi:10.1016/j.biopsych.2008.04.025.

van der Doef, T.F., de Witte, L.D., Sutterland, A.L., Jobse, E., 
JID: NEUPSY

[m6+;January 5, 2019;0:41]

13

Yaqub, M., Boellaard, R., de Haan, L., Eriksson, J., Lammertsma, A.A., Kahn, R.S., van Berckel, B.N.M., 2016. In vivo (R)-[11C]PK11195 PET imaging of 18kDa translocator protein in recent onset psychosis. NPJ Schizophr 2, 16031. doi:10.1038/ npjschz.2016.31.

van Kesteren, C.F.M.G., Gremmels, H., de Witte, L.D., Hol, E.M., Van Gool, A.R., Falkai, P.G., Kahn, R.S., Sommer, I.E.C., 2017. Immune involvement in the pathogenesis of schizophrenia: a meta-analysis on postmortem brain studies. Transl. Psychiatry 7, e1075. doi:10.1038/tp.2017.4.

Vandesompele, J., De Preter, K., Pattyn, F., Poppe, B., Van Roy, N., De Paepe, A., Speleman, F., 2002. Accurate normalization of real-time quantitative RT-PCR data by geometric averaging of multiple internal control genes. Genome Biol. 3 (7) RESEARCH0034.

Volk, D.W., Chitrapu, A., Edelson, J.R., Roman, K.M., Moroco, A.E., Lewis, D.A., 2015. Molecular mechanisms and timing of cortical immune activation in schizophrenia. Am. J. Psychiatry 172, 1112-1121. doi:10.1176/appi.ajp.2015.15010019.

Volk, D.W., Moroco, A.E., Roman, K.M., Edelson, J.R., Lewis, D.A., 2018. The role of the nuclear factor- $\kappa \mathrm{b}$ transcriptional complex in cortical immune activation in schizophrenia. Biol. Psychiatry 18 31629-31629 doi:10.1016/j.biopsych.2018.06.015.

Webster, M.J., O'Grady, J., Kleinman, J.E., Weickert, C.S., 2005. Glial fibrillary acidic protein mRNA levels in the cingulate cortex of individuals with depression, bipolar disorder and schizophrenia. Neuroscience 133, 453-461. doi:10.1016/j.neuroscience. 2005.02.037.
Wierzba-Bobrowicz, T., Lewandowska, E., Lechowicz, W., Stepień, T., Pasennik, E., 2005. Quantitative analysis of activated microglia, ramified and damage of processes in the frontal and temporal lobes of chronic schizophrenics. Folia Neuropathol. 43, 81-89.

Xiang, Y.-T., Wang, C.-Y., Weng, Y.-Z., Bo, Q.-J., Chiu, H.F.K., Chan, S.S.M., Lee, E.H.M., Ungvari, G.S., 2011. Predictors of relapse in Chinese schizophrenia patients: a prospective, multicenter study. Soc. Psychiatry Psychiatr. Epidemiol. 46, 13251330. doi:10.1007/s00127-010-0304-1.

Xu, H.M., Wei, J., Hemmings, G.P., 1994. Changes of plasma concentrations of interleukin-1 alpha and interleukin- 6 with neuroleptic treatment for schizophrenia. Br. J. Psychiatry 164, 251253. doi:10.1192/bjp.164.2.251.

Zabala, A., Rapado, M., Arango, C., Robles, O., de la Serna, E., González, C., Rodríguez-Sánchez, J.M., Andrés, P., Mayoral, M., Bombín, I., 2010. Neuropsychological functioning in early-onset first-episode psychosis: comparison of diagnostic subgroups. Eur. Arch. Psychiatry Clin. Neurosci. 260, 225-233. doi:10.1007/ s00406-009-0046-9.

Zotova, E., Bharambe, V., Cheaveau, M., Morgan, W., Holmes, C., Harris, S., Neal, J.W., Love, S., Nicoll, J.A.R., Boche, D., 2013. Inflammatory components in human Alzheimer's disease and after active amyloid- $\beta 42$ immunization. Brain 136, 2677-2696. doi:10.1093/brain/awt210.

Please cite this article as: I. López-González, R. Pinacho and È. Vila et al., Neuroinflammation in the dorsolateral prefrontal cortex in elderly chronic schizophrenia, European Neuropsychopharmacology, https://doi.org/10.1016/j.euroneuro.2018.12.011 